\title{
Review
}

Journal of Innate

Immunity
J Innate Immun 2011;3:216-226

DOI: $\underline{10.1159 / 000325265}$
Received: February 11, 2011

Accepted after revision: February 12, 2011

Published online: March 29, 2011

\section{Molecular Mechanisms of Natural Killer Cell Activation}

\author{
Yenan T. Bryceson $^{\mathrm{a}}$ Samuel C.C. Chiang ${ }^{\mathrm{a}}$ Stephanie Darmanin ${ }^{\mathrm{a}}$ Cyril Fauriat $^{\mathrm{b}}$ \\ Heinrich Schlums ${ }^{\text {a }}$ Jakob Theorell ${ }^{\text {a Stephanie M. Wood }}{ }^{\text {a }}$ \\ ${ }^{a}$ Center for Infectious Medicine, Department of Medicine, Karolinska Institutet, Karolinska University

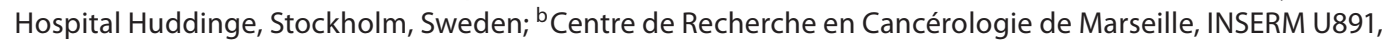 \\ Marseille, France
}

\section{Key Words}

Natural killer cells $\cdot$ Perforin · Munc13-4 - c-Cbl • VAV1 • Wiskott-Aldrich syndrome protein

\begin{abstract}
With an array of activating and inhibitory receptors, natural killer (NK) cells can specifically eradicate infected and transformed cells. Target cell killing is achieved through directed release of lytic granules. Recognition of target cells also induces production of chemokines and cytokines that can coordinate immune responses. Upon contact with susceptible cells, a multiplicity of activating receptors can induce signals for adhesion. Engagement of the integrin leukocyte functional antigen-1 mediates firm adhesion, provides signals for granule polarization and orchestrates the structure of an immunological synapse that facilitates efficient target cell killing. Other activating receptors apart from leukocyte functional antigen-1 signal for lytic granule exocytosis, a process that requires overcoming a threshold for activation of phospholipase C- $\gamma$, which in turn induces STIM1- and ORAl1-dependent store-operated $\mathrm{Ca}^{2+}$ entry as well as exocytosis mediated by the SNARE-containing protein syntaxin-11 and regulators thereof. Cytokine and chemokine release follows a different secretory pathway which also requires phospholipase $\mathrm{C}-\gamma$ activation and store-operated $\mathrm{Ca}^{2+}$ entry. Recent studies of human NK cells have provided insights into a hier-
\end{abstract}

archy of effector functions that result in graded responses by NK cell populations. Responses display cellular heterogeneity and are influenced by environmental cues. This review highlights recent knowledge gained on the molecular pathways for and regulation of NK cell activation.

Copyright $\odot 2011$ S. Karger AG, Basel

\section{Introduction}

Natural killer (NK) cells are considered to represent an arm of the innate immune system, as their effector functions are controlled by a repertoire of germline-encoded receptors that do not undergo somatic recombination $[1,2]$. However, similar to other lymphocyte subsets such as T and B cells, NK cells may manifest adaptive features [3]. NK cells participate in early defense against intracellular microbial infections and several types of tumors and may also be implicated in autoimmunity and hypersensitivity reactions [4-6]. NK cell-mediated resistance to intracellular pathogens and immunosurveillance of tumors involves both interferon (IFN)- $\gamma$ secretion and perforin-dependent target cell elimination $[7,8]$. NK cells may also instruct and shape adaptive immune responses through cytokine release or by direct interaction with dendritic cells [9]. Furthermore, NK cells can kill allogeneic cells in the setting of hematopoietic stem

\section{KARGER}

Fax +41613061234

E-Mail karger@karger.ch

www.karger.com
(C) 2011 S. Karger AG, Basel

$1662-811 X / 11 / 0033-0216 \$ 38.00 / 0$

Accessible online at:

www.karger.com/jin
Dr. Yenan T. Bryceson

Center for Infectious Medicine, Department of Medicine

Karolinska Institutet, Karolinska University Hospital Huddinge

SE-14186 Stockholm (Sweden)

Tel. +4685858 1158, E-Mail yenan.bryceson@ki.se 


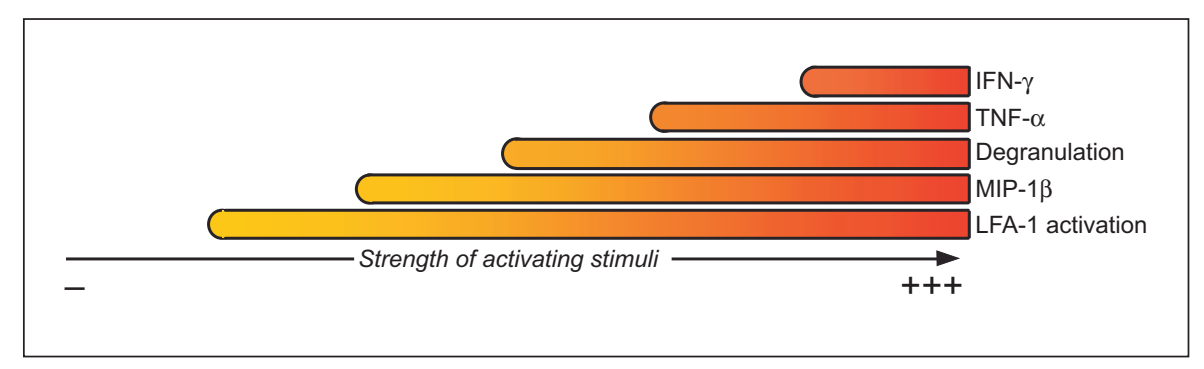

Fig. 1. Relative signal strength required for induction of different NK cell responses. The figure depicts the relative signal strength required for induction of different NK cell responses such as inside-out signals for LFA-1 (detected as LFA-1 conformational changes), degranulation (surface expression of CD107a), chemokine secretion (MIP-1 $\alpha$ and MIP-1 $\beta$ secretion) and cytokine se-

cell transplantation, and thus, have potential in immunotherapy of certain malignancies [10].

NK cells and cytotoxic T cells (CTLs) are thought to share mechanisms for target cell elimination. Both NK cell and CTL cytotoxicity relies on the directed release of the contents of lytic granules, which are specialized secretory lysosomes that contain perforin, granzymes and Fas ligand $[11,12]$. However, both in vitro and in vivo imaging studies comparing target cell recognition by NK cells and CTLs suggest some noteworthy distinctions. In vitro, CTLs rapidly establish cytoskeletal polarity, whereas NK cells are more tentative in their interactions with target cells [13]. In vivo, CTLs form stable contacts with tumor cells expressing cognate antigen, whereas NK cells mainly establish dynamic contacts [14]. These observations suggest significant differences in the molecular machinery underlying NK cell and CTL recognition and elimination of target cells.

Recent studies of NK cell responses have highlighted considerable heterogeneity among human peripheral blood NK cells and hierarchies in terms of the strength of the activating stimuli for induction of specific responses [15-17]. Inside-out signals for leukocyte functional antigen (LFA)-1-mediated adhesion exhibit a low threshold for activation, induction of chemokines such as macrophage inflammatory protein (MIP)- $1 \beta$ requires stronger activating stimuli, whereas degranulation and production of cytokines such as tumor necrosis factor (TNF)- $\alpha$ and IFN- $\gamma$ display the most stringent requirements for induction (fig. 1). Some of the functional heterogeneity in NK cell populations can be accounted for by differences in cellular differentiation and education [17-21]. In humans, relatively immature CD56 $6^{\text {bright }} \mathrm{NK}$ cells excel at cretion (IFN- $\gamma$ and TNF- $\alpha$ ). With regard to the kinetics of different responses, conformational changes in LFA-1 can be detected within seconds of activation, degranulation occurs within minutes, chemokine secretion within half an hour, and cytokine secretion after approximately $6 \mathrm{~h}$ of stimulation. Adapted from Fauriat et al. [17]. cytokine production in response to exogenous cytokines such as interleukin (IL)-2, IL-12, IL-15 and IL-18. However, CD56 $6^{\text {bright }} \mathrm{NK}$ cells express low levels of perforin, and are consequentially less cytotoxic than more mature CD56 ${ }^{\mathrm{dim}} \mathrm{NK}$ cells, and do not as readily produce cytokines in response to target cell recognition. Transitory CD56 ${ }^{\text {dim }} \mathrm{CD} 62 \mathrm{~L}^{+} \mathrm{CD} 57^{-} \mathrm{NK}$ cells produce significant IFN- $\gamma$ in response to exogenous cytokines, display higher levels of perforin expression and the ability to mediate cytotoxicity, and can produce ample amounts of cytokines in response to target cell recognition. Finally, terminally differentiated $\mathrm{CD} 56^{\mathrm{dim}} \mathrm{CD} 62 \mathrm{~L}^{-} \mathrm{CD} 57^{+} \mathrm{NK}$ cells express high levels of perforin, display potent cytotoxic capacity and exhibit strong production of cytokines in response to target cell recognition. However, the response of $\mathrm{CD} 56^{\mathrm{dim}} \mathrm{CD} 62 \mathrm{~L}^{-} \mathrm{CD} 57^{+} \mathrm{NK}$ cells to exogenous cytokines is blunted. In parallel to the continuous maturation process, recognition of self major histocompatibility complex class I molecules by inhibitory receptors potentiates NK cell responses. However, superimposing differentiation and education processes on NK cell functionality does not fully explain the heterogeneity in NK cell responses. Studies have revealed that the thresholds for effector responses are highly dynamic and may use different molecular pathways depending on cytokine activation [22]. Further molecular insights are required into the factors regulating the delicate balance in NK cell responsiveness, with too little possibly resulting in impaired immunity to infection and predisposition to malignancies, and too much potentially eliciting autoimmunity or hypersensitivity reactions. Here, we review recent insights into the molecular mechanisms of NK cell activation upon interaction with target cells. 


\section{NK Cell Receptor Signaling}

A multitude of activating NK cell receptors that belong to different receptor families and contain highly divergent cytoplasmic signaling domains have been described. The signaling pathways orchestrated by many activating NK cell receptors are not well defined [23, 24]. In contrast, structurally distinct inhibitory NK cell receptors all contain immunoreceptor tyrosine-based inhibition motifs. The signaling by such motifs has been extensively studied and is mainly mediated through activation of tyrosine phosphatases such as SHP-1 that can dephosphorylate the guanine exchange factor VAV1, as well as through phosphorylation of the adaptor Crk by the tyrosine kinase c-Abl $[25,26]$. Some inhibitory receptors engage other negative regulators such as SHIP, an inositol 5-phosphatase, and the Src family tyrosine kinase CSK that phosphorylates and negatively regulates other Src family kinases. NK cell activating and inhibitory receptors, their ligands and proximal signaling are detailed in figure 2. In the following paragraph, more detailed background is provided for select activating receptors expressed on NK cells.

The low-affinity Fc receptor CD16 is a prototypical NK cell activating receptor that can facilitate antibodydependent cellular cytotoxicity against IgG-coated cells. Engagement of CD16 induces Src family kinase-dependent phosphorylation of immunoreceptor tyrosine-based activation motifs on the adaptor chains $\mathrm{CD} 3 \zeta$ and $\mathrm{Fc} \varepsilon \mathrm{R} \gamma$, which in turn recruit and activate SYK and ZAP-70 tyrosine kinases for downstream signaling [27]. Engagement of CD16 on NK cells is sufficient to induce NK cell degranulation [15]. Other NK cell receptors have been termed 'coactivation receptors', as engagement of each receptor alone is insufficient to induce activation in freshly isolated peripheral blood NK cells, whereas engagement of specific pairwise combinations of receptors can induce synergistic intracellular $\mathrm{Ca}^{2+}$ mobilization as well as degranulation and cytokine production $[16,28]$. An example of such a coactivating receptor pair is 2B4 (CD244) and DNAM-1 (CD226). 2B4 contains cytoplasmic immunoreceptor tyrosine-based switch motifs. These motifs are phosphorylated and can recruit either phosphatases for negative regulation of NK cell function, or, via the adaptor SAP, the SRC kinase Fyn for positive regulation of NK cell function [29-31]. In human NK cells, 2B4 is typically activating unless cells are deficient in SAP, which is the case in the primary immunodeficiency $\mathrm{X}$ linked lymphoproliferative type 1 caused by mutations in SH2D1A $[29,32]$. The cytoplasmic domain of DNAM-1 is phosphorylated by PKC [33]. Signaling further downstream by DNAM-1 in NK cells is not well characterized. NKG2D is another coactivating receptor that may synergize with 2B4. NKG2D is associated with the adaptor DAP10 and signals through recruitment of either phosphatidylinositol-3-kinase (PI3K) or the adaptor Grb2 [34].

Taken together, potent NK cell effector functions such as cytotoxicity and cytokine production require dynamic integration of signals derived from multiple receptors. The following sections will focus on advances in our understanding of the molecular processes underlying NK cell effector responses.

\section{Contact and Adhesion}

A first step in responses to pathogen infections or tumors involves recruitment of $\mathrm{NK}$ cells to the site of inflammation, infection or transformation. NK cells express several chemokine receptors, and the mechanisms of NK cell trafficking to inflamed tissues have recently been reviewed elsewhere [35]. With regard to a role for NK cells as sentinels in immunosurveillance of virally infected or transformed cells, the degree to which NK cells constitutively traffic to noninflammed tissues is not well understood. However, how NK cells detect and discriminate target cells has been extensively studied. The initial contact between NK cells and a target cell may involve any of a number of receptors. A variety of activating receptors, including CD16, 2B4, NKG2D, DNAM-1 and LFA-1 itself, can rapidly induce insideout signals for activation of LFA-1 in freshly isolated human NK cells, thus promoting adhesion [16]. As opposed to activating receptors that promote adhesion to target cells, inhibitory receptors can abrogate target cell adhesion [36]. For example, coengagement of NKG2A by its ligand HLA-E on target cells overrides inside-out signals for activation of LFA-1 from multiple activating NK cell receptors [16]. Notably, LFA-1 conformationspecific monoclonal antibodies display a heterogeneous staining pattern on freshly isolated human NK cells, revealing that a subset of NK cells exhibit LFA-1 in an active, ligand-binding, extended conformation [16]. Treatment of NK cells with pharmacological inhibitors of SRC family kinases, PI3K, or phospholipase C (PLC)- $\gamma$ diminishes the basal level of extended LFA-1 [16]. Thus, tonic signals dynamically maintain an active LFA-1 conformation in a subset of NK cells, consistent with the signaling-dependent ability of resting NK cells to bind 


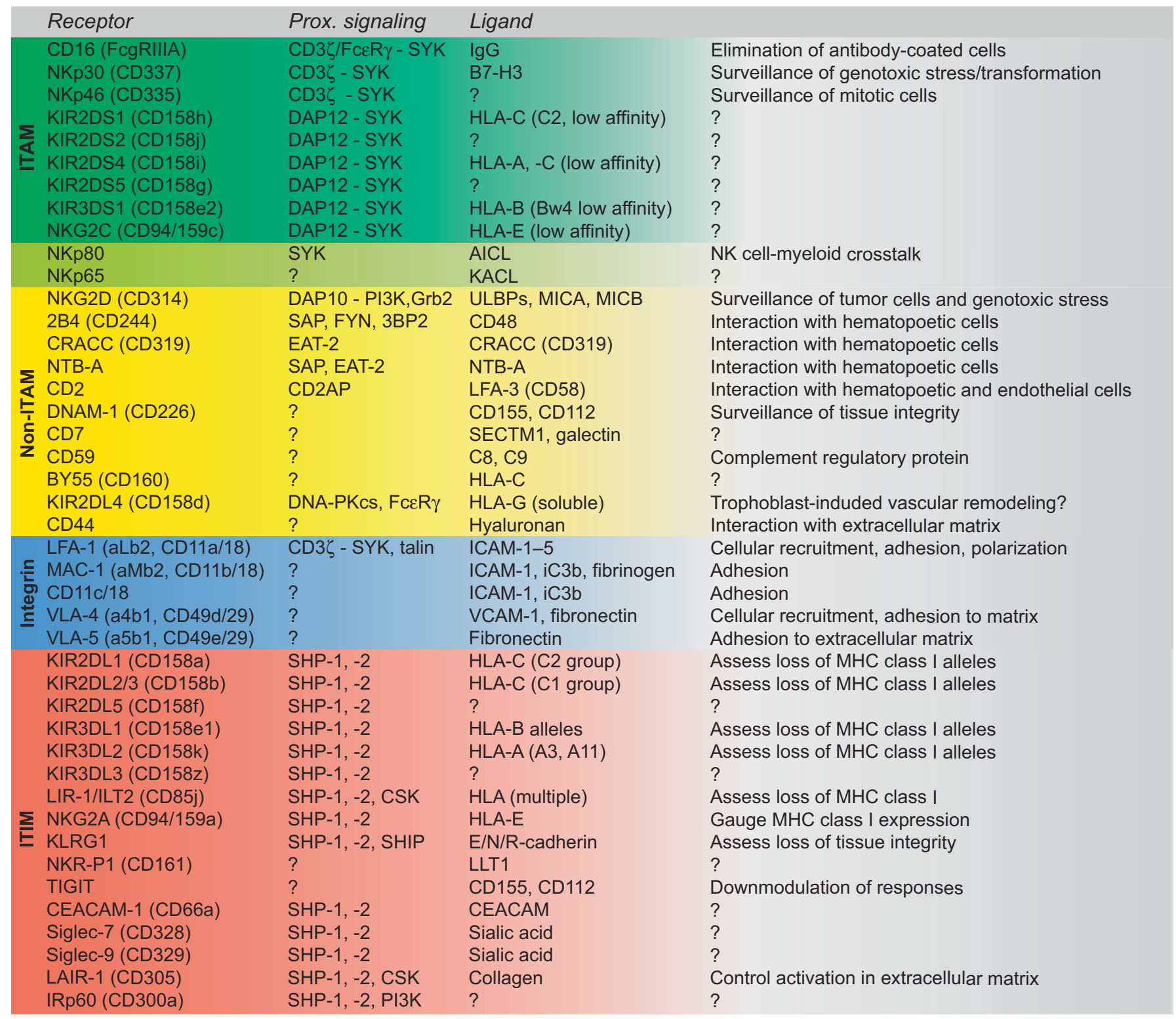

Fig. 2. Overview of NK cell activating and inhibitory receptor signaling, ligands and function. The strongest activating receptors associate with immunoreceptor tyrosine-based activation motif (ITAM)-coupled adaptor proteins (dark green). Other activating receptors contain hemi-immunoreceptor tyrosine-based activation (ITAM) motifs in their cytoplasmic domains (light green). A number of other receptors have been implicated in NK cell acti-

intercellular adhesion molecule 1 [37]. The presence of active, extended LFA-1 on freshly isolated human NK cells, a feature not shared with resting human T cells, may in part explain the more dynamic nature of NK cell interactions with target cells as compared to that of CTL $[13,14]$.

Mechanisms of NK Cell Cytotoxicity vation (yellow), some of which are coactivating receptors. Adhesion receptors (blue) may also contribute signals to NK cell activation. Inhibitory receptors (yellow) intersect activating signals via immunoreceptor tyrosine-based inhibition motifs (ITIMs) in their cytoplasmic domains that generally recruit phosphatases. $\mathrm{MHC}=$ Major histocompatibility class.

The signals for inside-out activation of LFA-1 and adhesion induced upon contact with the multitude of activating receptors in NK cells are not well defined [24]. As previously emphasized, the activating NK cell receptors have distinct cytoplasmic domains, and thus, are likely to act as platforms for different signaling com-

J Innate Immun 2011;3:216-226 
plexes. Live cell imaging of NK cells on supported planar lipid bilayers carrying ligands for LFA-1, NKG2D, 2B4 and CD16 has shown that these receptors induce diverse behaviors [38]. NK cells actively crawl over surfaces with ligands for LFA-1 or NKG2D, ligands for 2B4 induce receptor clustering but not active movement, and ligands for CD16 induce synapse formation and degranulation. With regard to signals for inside-out activation of LFA-1, phosphorylation and activation of the guanine exchange factor and actin regulator VAV1 have been postulated to be a common denominator of signaling pathways downstream of activating receptors, including LFA-1 itself. Concomitantly, VAV1 phosphorylation provides a point at which inhibitory receptor signals can oppose signals from activating receptors. Specifically, phosphorylated VAV1 is a substrate of SHP1 [39]. In terms of cell morphology and behavior, such inhibitory signals in smaller, asymmetrical synapses facilitate migration [40]. Recently, a study by Awasthi et al. [41] found that NK cells from mice deficient in the Ras family GTPase Rap1b show defective accumulation of LFA-1 upon binding to surfaces coated with the ligand intercellular adhesion molecule 1 or stimulation with phorbol myristate acetate and ionomycin. Interestingly, Raplb deficiency did not impair phosphorylation of VAV1 upon engagement of NKG2D or target cell lysis. However, activation of Raplb-deficient NK cells resulted in reduced phosphorylation of p21-activated kinases 1, 2 and 3, a selective impairment in phosphorylation of the mitogen-activated protein kinase ERK, as well as in defective secretion of chemokines and cytokines. Furthermore, it was demonstrated that Rablb colocalizes with the microtubule-organizing center (MTOC), regulates the architecture of the MTOC and facilitates the formation of an IQGAP1-dependent perinuclear signalosome which is a site of ERK phosphorylation [41]. Directly linked to the extension of the LFA-1 ectodomain, talin binding to the cytoplasmic tail of LFA-1 stabilizes the active, ligand-binding extended conformation. Talin-1-deficient mouse NK cells are defective in LFA-1-mediated adhesion [42]. Interestingly, Cdc42 and Wiskott-Aldrich syndrome protein (WASP) are required for chemokine-induced inside-out signals in freshly isolated human NK cells, as NK cells from WASP patients display defective activation of LFA-1 [43]. In human IL-2-expanded NK cells, knockdown of the adaptor protein CrkL impaired NK cell adhesion, granule polarization and granule secretion downstream of NKG2D engagement [44]. CrkL was shown to facilitate NKG2D signaling downstream of PI3K activation and, in turn, activate Rap1. Moreover, phosphorylation of HS1, the hematopoietic cell-specific homolog of cortactin, at Tyr397, is required for LFA-1-dependent adhesion by human IL-2-expanded NK cells upon engagement of LFA-1 and NKG2D [45]. In this setting, mutation of Tyr397 to Phe397 attenuated phosphorylation of VAV1.

Together, these data suggest important roles for WASP and HS1 in the pathways leading to VAV1 phosphorylation and LFA-1-dependent adhesion, possibly also involving CrkL and Rap1. Rap1 participates in inside-out signals for LFA-1 in T cells [46]. Future experiments need to address how membrane-proximal signals downstream of specific NK cell activating receptors couple to signals for NK cell adhesion, including inside-out signals for ligandbinding, extended LFA-1 and signals for clustering of LFA-1 that together may cooperatively regulate NK cell adhesion to target cells.

\section{Granule Polarization and Maturation}

A key role for LFA-1 in promoting perforin-containing granule polarization towards the target cell, facilitating efficient cytotoxicity, has previously been shown [15, 47]. Moreover, such granule polarization towards the immune synapse is the result of two different molecular processes. First, granules rapidly converge in dynein-dependent, minus end-directed motion to the MTOC [48], as initially described in T cells [49]. In the NK cell line YTS, antibody-mediated blockade of LFA-1 impairs granule convergence at the MTOC upon target cell contact, suggesting that LFA-1-mediated signals facilitate this process [48]. Second, following convergence of the granules and within minutes, the MTOC and granules polarize towards the interaction site in an LFA-1-dependent manner $[15,48]$. In an elegant set of experiments, Mace and colleagues $[42,50]$ generated mouse NK cells from embryonic stem cells of knockout mice to delineate LFA-1-mediated outside-in signals. These experiments have demonstrated that talin is required for recruitment of WASP, Arp2/3, vinculin and actin, as well as for polarization of lytic granules downstream of LFA-1 engagement. Furthermore, WASP is required for the accumulation of F-actin at the synapse, and the recruitment of WASP is facilitated by talin-dependent recruitment and activation of phosphatidylinositol 4-phosphate 5-kinase type I $\gamma$ (PI5KI $\gamma$ ) [50]. The product of PI5KI $\gamma$ is phosphatidylinositol $(4,5)$-bisphosphate. Contrasting results in mouse cells, silencing of PI5KI $\alpha$ or PI5KI $\gamma$ in 
human NK cells has previously been reported to impair lytic granule exocytosis but not granule polarization [51]. Moreover, silencing of WASP-interacting protein in the human NK cell line YTS impairs lytic granule polarization but does not affect formation of conjugates with target cells [52]. Interestingly, the second messenger diacylglycerol has been shown to be required for MTOC polarization and cytotoxicty by CTL [53], but to what extent diacylglycerol regulates LFA-1-mediated MTOC polarization in NK cells remains to be established. Recently, signaling for granule polarization by LFA-1 in IL2-expanded human NK cells was shown to also involve $\mathrm{CD} 3 \zeta$ chain phosphorylation, SYK recruitment and activation, as well as PLC- $\gamma$ activation [54]. Activation of PLC- $\gamma$ results in hydrolysis of phosphatidylinositol $(4,5)$-bisphosphate to generate the second messengers diacylglycerol and inositol $(1,4,5)$-trisphosphate. Downstream of LFA-1, PLC- $\gamma$ activation leads to PKC activation and pharmacological inhibition of PLC- $\gamma$-abrogated granule polarization [54]. Of note, also in YTS cells, the ubiquitously expressed protein phosphate 1 regulatory subunit $9 \mathrm{~B}$ is recruited to immune synapses upon LFA-1 engagement and is reported to be required for maintenance of the F-actin cytoskeleton [55]. Upon recognition of susceptible target cells, the tyrosine kinase PYK2 is also recruited to the immune synapse, and transfection of dominant negative PYK2 blocks MTOC and paxillin movement to the synapse [56]. Recently, pharmacological inhibition or knockdown of the mitogen-activated protein kinase JNK was also shown to be required for paxillin recruitment to the immune synapse, in addition to MTOC and granule polarization in human NK cells [57].

In an interesting study, Butler and Cooper [58] compared the role of the actin nucleators Arp $2 / 3$ and hDial for cytotoxicity by IL-2-expanded NK cells. Knockdown of Arp2/3 in human NK cells diminished cell adhesion, reduced actin assembly at the immune synapse and impaired cytotoxicity. Specifically, Arp2/3 knockdown affected VAV1 activation and recruitment of active PYK2 downstream of LFA-1 engagement. In contrast, knockdown of hDial did not disrupt actin assembly at the immune synapse, but reduced cytoxicity by impairing lytic granule polarization.

In summary, these studies suggest pathways involving talin, WASP, WASP-interacting protein, PYK, JNK and paxillin, as well as CD3 $\zeta$, SYK and PLC- $\gamma$ for granule polarization. Furthermore, how the formin hDial contributes to LFA-1-mediated polarization in NK cells needs to be further assessed.

Mechanisms of NK Cell Cytotoxicity

\section{Granule Maturation and Exocytosis}

Vesicle exocytosis is a requirement for NK cell cytotoxicity [28]. A pathway involving PI3K, RAC1, p21-activated kinase 1 and ERK has been reported to play a critical role in cytotoxicity mediated by the NK cell line NK92 and IL-2-expanded NK cells [59]. More recent studies of knockout mice have demonstrated an essential role for PLC- $\gamma$ in granule exoctyosis $[60,61]$. NK cells from these mice adhered to target cells, polarized granules, but failed to mediate cytotoxicity. Following activation of PLC- $\gamma$, inositol $(1,4,5)$-trisphosphate can trigger cytoplasmic release of $\mathrm{Ca}^{2+}$ from the endoplasmic reticulum (ER). Engagement of CD16 is sufficient to induce robust intracellular $\mathrm{Ca}^{2+}$ mobilization, whereas several other receptors do not. Rather, coactivation receptors trigger intracellular $\mathrm{Ca}^{2+}$ mobilization when engaged in specific pairwise combinations [28]. Recent data suggest that the molecular basis for such coactivation involves overcoming a threshold for activation of VAV1 that is set by the ubiquitin ligase c-Cbl [62]. VAV1 overexpression or c-Cbl knockdown each circumvented the necessity for synergy, as engagement of either NKG2D or 2B4 alone became sufficient for activation. Notably, inhibition of NK cell cytotoxicity by NKG2A binding to HLA-E on target cells was dominant over synergistic activation, even after c$\mathrm{Cbl}$ knockdown. Following PLC- $\gamma$ activation, inositol $(1,4,5)$-trisphosphate-mediated $\mathrm{Ca}^{2+}$ release from the endoplasmic reticulum results in depletion of $\mathrm{Ca}^{2+}$ stores and aggregation of the endoplasmic reticulum $\mathrm{Ca}^{2+}$ sensor STIM1. Aggregation of STIM1 transactivates the plasma membrane $\mathrm{Ca}^{2+}$ release-activated $\mathrm{Ca}^{2+}$ channel ORAI1, leading to store-operated $\mathrm{Ca}^{2+}$ entry (SOCE). Remarkably, NK cells from patients with mutations in either STIM1 or ORAI1 display defective degranulation, demonstrating a requirement for ORAI1-mediated SOCE for lytic granule exocytosis [63]. Importantly, ORAI1 deficiency or pharmacological inhibition of SOCE does not affect signals for adhesion or granule polarization [63]. How signals for PLC- $\gamma$ activation by LFA- 1 and CD16 selectively induce polarization or granule release, respectively, remains to be elucidated [54].

The requirement for SOCE in NK cell exocytosis has parallels with the requirement of high $\mathrm{Ca}^{2+}$ concentrations for exocytosis of vesicles in neurons [64]. In neurons, $\mathrm{Ca}^{2+}$-binding proteins that facilitate exocytosis are synaptotagmin and Munc13-1. The $\mathrm{Ca}^{2+}$-binding proteins that facilitate NK cell or CTL exocytosis have so far not been clearly defined. Synaptotagmin VII has been proposed to be a candidate $\mathrm{Ca}^{2+}$ sensor for lytic granule

J Innate Immun 2011;3:216-226 
exocytosis based on experiments assessing the cytotoxic function of mouse synaptotagmin VII-deficient CTL [65]. Autosomal recessive mutations in the gene encoding Munc13-4, a homolog of neuronal Munc13-1, are associated with early-onset hemophagocytic lymphohistiocytosis [66]. The clinical presentation of Munc13-4 deficiency is comparable to that of perforin deficiency, documenting an important role for cytotoxic lymphocytes in maintaining immune homeostasis. Importantly, Munc13-4 deficiency results in defective NK cell cytotoxicity $[22,67]$. Because Munc13-4 contains two C2 $\mathrm{Ca}^{2+}$ binding domains, Munc13-4 might also represent a $\mathrm{Ca}^{2+}$ sensor for cytotoxic lymphocyte exocytosis. Furthermore, deficiency in the SNARE motif containing protein syntaxin-11 (Stx11) or the binding partner and regulator Munc18-2, as well as deficiency in the small GTPase Rab27a, abolishes degranulation by freshly isolated peripheral blood NK cells [22, 68-70], in line with a clinical phenotype of hemophagocytic lymphohistiocytosis. In Rab27a-, Munc13-4- and Stx11-deficient cytotoxic lymphocytes, lytic granules still polarize towards the target cell $[22,66,71]$. In CTL, GTP-bound Rab27a can bind the synaptotagmin-like proteins SLP1 and SLP2 and might facilitate tethering of lytic granule-associated Rab27a to the plasma membrane [72, 73]. Munc13-4 is thought to mediate priming of the granules for vesicle fusion [66], as Munc13-1 does through interactions with Stx1 in neurons [64]. Stx11 is considered to function in the granule fusion with the plasma membrane. Importantly, membrane fusion is energetically demanding and requires the force produced through zippering of a 4-strand molecular complex of SNARE domains from 3 or 4 different proteins. The interaction partners of Stx 11 have not been defined. SNAP23, containing two SNARE domains, has been hypothesized to localize with Stx11 on the plasma membrane and facilitate fusion through lytic granulebound VAMP7 or VAMP8 [65]. Several steps in the pathway leading to lytic granule release remain obscure and, thus, represent a challenge for future research.

Recent studies in CTLs and NK cells have revealed that neither Rab27a nor Munc13-4 is constitutively associated with lytic granules. Rather, they colocalize with perforin-containing granules following cellular activation [74, 75]. Although Munc13-4 is an effector of GTPbound Rab27a, Rab27a or Munc13-4 colocalization was preferentially induced by engagement of LFA-1 or activating receptors such as CD16, respectively [75]. These observations reveal multilayered control of lytic granule exocytosis, which might represent a mechanism for preventing inappropriate release of such deadly proteins.
Furthermore, results suggest that distinct endosomal compartments fuse prior to lytic granule fusion with the plasma membrane $[74,75]$. The precise nature and raison d'être for such endosomal fusion events remains to be investigated.

Besides intracellular $\mathrm{Ca}^{2+}$ mobilization, evidence suggests that other molecular pathways govern granule exocytosis and thus the efficiency of lymphocyte cytotoxicity. ERK has long been implicated in lytic granule exocytosis [28]. The Ras guanyl nucleotide-releasing protein-1 contributes to cytotoxicity and cytokine production in IL-15-expanded NK cells and acts downstream of PLC- $\gamma$, integrating $\mathrm{Ca}^{2+}$ and diacylglycerol signals for activation of the Ras-ERK pathway [76]. Moreover, the mitogenactivated protein kinase scaffolding protein KSR1 is required for optimal ERK activation. KSR-deficient mouse NK cells displayed no defect in the formation of conjugates with target cells, but lytic granule polarization and target cell killing was impaired [77]. Lytic granule exocytosis was not directly assessed.

Finally, for efficient cytotoxicity, lytic granules must traverse the actin-rich immunological synapse for exocytosis to occur. The ATP-dependent actin motor protein myosin IIA has been shown to associate with lytic granules in NK cells [78]. NK cells from humans with the May-Hegglin anomaly caused by autosomal dominant mutations in the gene encoding myosin IIA display reduced NK cell degranulation and cytotoxicity. Thus, myosin IIA may play a role in mediating lytic granule actin traversing for exocytosis.

In summary, biological and genetic experiments have identified a set of proteins required for lytic granule exocytosis. Still, much remains to be elucidated in terms of how signals for granule polarization, maturation and exocy tosis are intricately regulated by membrane proximal signaling events, bifurcating and converging at critical signaling nodes.

\section{Chemokine and Cytokine Production}

Target cell recognition by freshly isolated human NK cells induces expression of a set of chemokines, including MIP- $1 \alpha$, MIP-1 $\beta$ and RANTES, as well as cytokines TNF- $\alpha$ and IFN- $\gamma$ [17]. Chemokines are rapidly induced within $1 \mathrm{~h}$ of stimulation, whereas secretion occurs several hours after activation. Importantly, experiments varying the signaling input for NK cell activation have revealed a hierarchy in requirements for induction of chemokines and cytokines, with chemokines induced by 
weakly activating signals, degranulation induced by intermediate levels of activating stimuli, and cytokines requiring the strongest activation (fig. 1). This hierarchy is reflected in the requirements for induction of different effector responses. PLC- $\gamma$ is required for all responses $[60,61$, Y.T.B., unpubl. data]. Deficiency in SOCE, as seen in NK cells from humans with autosomal recessive STIM1 and ORAI1 mutations, results in defective degranulation and cytokine production, but only partially impairs chemokine production [63]. Notably, NK cells from PI3K p110 $\delta$-deficient mice displayed selectively impaired cytokine production, whereas knockout of both $\mathrm{p} 110 \delta$ and p110 $\gamma$ was required to impair cytotoxicity $[79,80]$. Moreover, PKC $\theta$-deficient mice displayed defective IFN- $\gamma$ transcription and secretion due to impaired JNK, AP-1 and NFAT activation [81]. NK cell-mediated cytotoxicity was not impaired in PKC $\theta$-deficient mice. Curiously, Rap1b deficiency in mice selectively impairs NK cell chemokine and cytokine production, but not cytotoxicity [41].

Thus, a few proteins, including PI3K p $110 \delta$ and PKC $\theta$, may be specifically required for transcription of cytokine genes. Further studies are required to understand how these proteins are integrated in the signaling pathways for NK cell activation and how engagement of different activating receptors controls their activity.

\section{Perspectives}

NK cell activation by target cells is achieved through dynamic engagement of multiple receptors. Recent advances are shedding light on the specific pathways instigated by a multitude of activating NK cell receptors. Remarkably, reductionistic studies of freshly isolated human NK cell interactions with lipid bilayers carrying ligands for multiple activating receptors have revealed highly organized molecular structures orchestrating bidirectional vesicular trafficking for target cell killing
[38]. Many of these molecular processes are still not well defined, and understanding of the spatiotemporal regulation of NK cell signaling remains a challenge. Whereas recent studies have provided considerable insights into the proteins required for exocytosis, retrieval of membranes is equally important to sustain NK cell responses. Dynamin-2-dependent endocytosis has been implicated in this process [82], but much remains to be studied with regard to the regulation of endocytic trafficking in NK cells. Target cell detachment is another facet of NK cell biology that so far has received little attention and that is required to support serial killing [83]. In patients carrying mutations in genes required for cytotoxic lymphocyte exocytosis, the degree to which NK cells are impaired is related to disease onset $[22,84]$. Cytokines may influence NK cell exocy tosis and target cell killing, but how thresholds for NK cell cytotoxicity and cytokine production are dynamically regulated is not well understood. IL-2 may induce an alternative, Stx11-independent pathway for vesicle exocytosis [22]. Interestingly, IL-2 also restores cytotoxicity by WASP-deficient NK cells [85]. Moreover, experiments have implicated IL-15-induced SOCS2 expression in downregulating PYK2 and augmenting NK cell effector functions [86]. A better molecular understanding of how NK cells regulate their effector responses may provide important insights into the pathogenesis of several diseases and pave the way for improved clinical use of NK cells for immunotherapy.

\section{Acknowledgements}

We thank colleagues for insightful discussions and apologize for those whose work has not been cited due to space constraints. We acknowledge the generous support from the Histocytosis Association of America, Mary Beve's Foundation, Clas Groschinsky's Memorial Fund, Shizu Matsumuras Donation, the Karolinska Institute Research Foundation, and Swedish Research Council (to Y.T.B.). S.M.W. is supported by a Marie Curie Fellowship.

\section{References}

$\checkmark 1$ Bryceson YT, Long EO: Line of attack: NK cell specificity and integration of signals. Curr Opin Immunol 2008;20:344-352.

$>2$ Lanier LL: Up on the tightrope: natural killer cell activation and inhibition. Nat Immunol 2008;9:495-502.

73 Biron CA: More things in heaven and earth: defining innate and adaptive immunity. Nat Immunol 2010;11:1080-1082.
-4 Vivier E, Tomasello E, Baratin M, Walzer T, Ugolini S: Functions of natural killer cells. Nat Immunol 2008;9:503-510.

5 Flodstrom-Tullberg M, Bryceson YT, Shi FD, Hoglund P, Ljunggren HG: Natural killer cells in human autoimmunity. Curr Opin Immunol 2009;21:634-640.
6 von Bubnoff D, Andres E, Hentges F, Bieber T, Michel T, Zimmer J: Natural killer cells in atopic and autoimmune diseases of the skin. J Allergy Clin Immunol 2010;125:60-68.

7 Lodoen MB, Lanier LL: Natural killer cells as an initial defense against pathogens. Curr Opin Immunol 2006;18:391-398. 
8 Vesely MD, Kershaw MH, Schreiber RD, Smyth MJ: Natural innate and adaptive immunity to cancer. Annu Rev Immunol 2010, Epub ahead of print.

-9 Ferlazzo G, Munz C: Dendritic cell interactions with NK cells from different tissues. J Clin Immunol 2009;29:265-273.

10 Malmberg KJ, Bryceson YT, Carlsten M, Andersson S, Bjorklund A, Bjorkstrom NK, Baumann BC, Fauriat C, Alici E, Dilber MS, Ljunggren HG: NK cell-mediated targeting of human cancer and possibilities for new means of immunotherapy. Cancer Immunol Immunother 2008;57:1541-1552.

-11 Dustin ML, Long EO: Cytotoxic immunological synapses. Immunol Rev 2010;235:2434.

12 Griffiths GM, Tsun A, Stinchcombe JC: The immunological synapse: a focal point for endocytosis and exocytosis. J Cell Biol 2010; 189:399-406.

$\checkmark 13$ Wulfing C, Purtic B, Klem J, Schatzle JD: Stepwise cytoskeletal polarization as a series of checkpoints in innate but not adaptive cytolytic killing. Proc Natl Acad Sci USA 2003; 100:7767-7772.

- 14 Deguine J, Breart B, Lemaitre F, Di Santo JP, Bousso P: Intravital imaging reveals distinct dynamics for natural killer and CD8(+) T cells during tumor regression. Immunity 2010;33:632-644.

-15 Bryceson YT, March ME, Barber DF, Ljunggren HG, Long EO: Cytolytic granule polarization and degranulation controlled by different receptors in resting NK cells. J Exp Med 2005;202:1001-1012.

-16 Bryceson YT, Ljunggren HG, Long EO: Minimal requirement for induction of natural cytotoxicity and intersection of activation signals by inhibitory receptors. Blood 2009; 114:2657-2666.

-17 Fauriat C, Long EO, Ljunggren HG, Bryceson YT: Regulation of human NK cell cytokine and chemokine production by target cell recognition. Blood 2010;115:2167-2176.

- 18 Bjorkstrom NK, Riese P, Heuts F, Andersson S, Fauriat C, Ivarsson MA, Bjorklund AT, Flodstrom-Tullberg M, Michaelsson J, Rottenberg ME, Guzman CA, Ljunggren HG, Malmberg KJ: Expression patterns of NKG2A, KIR, and CD57 define a process of CD56 ${ }^{\mathrm{dim}}$ NK-cell differentiation uncoupled from NK-cell education. Blood 2010;116: 3853-3864.

- 19 Anfossi N, Andre P, Guia S, Falk CS, Roetynck S, Stewart CA, Breso V, Frassati C, Reviron D, Middleton D, Romagne F, Ugolini S, Vivier E: Human NK cell education by inhibitory receptors for MHC class I. Immunity 2006;25:331-342.

-20 Juelke K, Killig M, Luetke-Eversloh M, Parente E, Gruen J, Morandi B, Ferlazzo G, Thiel A, Schmitt-Knosalla I, Romagnani C: CD62L expression identifies a unique subset of polyfunctional CD56 $6^{\mathrm{dim}} \mathrm{NK}$ cells. Blood 2010;116:1299-1307.
21 Lopez-Verges S, Milush JM, Pandey S, York VA, Arakawa-Hoyt J, Pircher H, Norris PJ, Nixon DF, Lanier LL: CD57 defines a functionally distinct population of mature NK cells in the human $\mathrm{CD} 56^{\mathrm{dim}} \mathrm{CD} 16^{+} \mathrm{NK}$-cell subset. Blood 2010;116:3865-3874.

-22 Bryceson YT, Rudd E, Zheng C, Edner J, Ma D, Wood SM, Bechensteen AG, Boelens JJ, Celkan T, Farah RA, Hultenby K, Winiarski J, Roche PA, Nordenskjold M, Henter JI, Long EO, Ljunggren HG: Defective cytotoxic lymphocyte degranulation in syntaxin-11 deficient familial hemophagocytic lymphohistiocytosis 4 (FHL4) patients. Blood 2007; 110:1906-1915.

23 Bryceson YT, March ME, Ljunggren HG, Long EO: Activation, coactivation, and costimulation of resting human natural killer cells. Immunol Rev 2006;214:73-91.

24 Watzl C, Long EO: Signal transduction during activation and inhibition of natural killer cells. Curr Protoc Immunol 2010; Chapter 11:Unit 11.9B.

25 Long EO: Negative signaling by inhibitory receptors: the NK cell paradigm. Immunol Rev 2008;224:70-84.

26 Peterson ME, Long EO: Inhibitory receptor signaling via tyrosine phosphorylation of the adaptor Crk. Immunity 2008;29:578-588.

27 Ting AT, Dick CJ, Schoon RA, Karnitz LM, Abraham RT, Leibson PJ: Interaction between lck and syk family tyrosine kinases in Fc gamma receptor-initiated activation of natural killer cells. J Biol Chem 1995;270: 16415-16421.

28 Bryceson YT, March ME, Ljunggren HG, Long EO: Synergy among receptors on resting NK cells for the activation of natural cytotoxicity and cytokine secretion. Blood 2006;107:159-166.

29 Tangye SG, Cherwinski H, Lanier LL, Phillips JH: 2B4-mediated activation of human natural killer cells. Mol Immunol 2000;37: 493-501.

30 Eissmann P, Beauchamp L, Wooters J, Tilton JC, Long EO, Watzl C: Molecular basis for positive and negative signaling by the natural killer cell receptor 2B4 (CD244). Blood 2005; 105:4722-4729.

31 Veillette A: NK cell regulation by SLAM family receptors and SAP-related adapters. Immunol Rev 2006;214:22-34.

- 32 Parolini S, Bottino C, Falco M, Augugliaro R, Giliani S, Franceschini R, Ochs HD, Wolf $\mathrm{H}$, Bonnefoy JY, Biassoni R, Moretta L, Notarangelo LD, Moretta A: X-linked lymphoproliferative disease. 2B4 molecules displaying inhibitory rather than activating function are responsible for the inability of natural killer cells to kill Epstein-Barr virusinfected cells. J Exp Med 2000;192:337-346.

33 Shibuya A, Lanier LL, Phillips JH: Protein kinase $\mathrm{C}$ is involved in the regulation of both signaling and adhesion mediated by DNAX accessory molecule-1 receptor. J Immunol 1998;161:1671-1676.
4 Upshaw JL, Arneson LN, Schoon RA, Dick CJ, Billadeau DD, Leibson PJ: NKG2D-mediated signaling requires a DAP10-bound Grb2-Vav1 intermediate and phosphatidylinositol-3-kinase in human natural killer cells. Nat Immunol 2006;7:524-532.

35 Gregoire C, Chasson L, Luci C, Tomasello E, Geissmann F, Vivier E, Walzer T: The trafficking of natural killer cells. Immunol Rev 2007;220:169-182.

36 Burshtyn DN, Shin J, Stebbins C, Long EO: Adhesion to target cells is disrupted by the killer cell inhibitory receptor. Curr Biol 2000;10:777-780.

37 Barber DF, Long EO: Coexpression of CD58 or CD48 with intercellular adhesion molecule 1 on target cells enhances adhesion of resting NK cells. J Immunol 2003;170:294299.

38 Liu D, Bryceson YT, Meckel T, Vasiliver-Shamis G, Dustin ML, Long EO: Integrin-dependent organization and bidirectional vesicular traffic at cytotoxic immune synapses. Immunity 2009;31:99-109.

-39 Stebbins CC, Watzl C, Billadeau DD, Leibson PJ, Burshtyn DN, Long EO: Vavl dephosphorylation by the tyrosine phosphatase SHP-1 as a mechanism for inhibition of cellular cytotoxicity. Mol Cell Biol 2003;23: 6291-6299.

40 Culley FJ, Johnson M, Evans JH, Kumar S, Crilly R, Casasbuenas J, Schnyder T, Mehrabi M, Deonarain MP, Ushakov DS, Braud V, Roth G, Brock R, Kohler K, Davis DM: Natural killer cell signal integration balances synapse symmetry and migration. PLoS Biol 2009; 7:e1000159.

-41 Awasthi A, Samarakoon A, Chu H, Kamalakannan R, Quilliam LA, ChrzanowskaWodnicka M, White GC 2nd, Malarkannan S: Raplb facilitates NK cell functions via IQGAP1-mediated signalosomes. J Exp Med 2010;207:1923-1938.

42 Mace EM, Monkley SJ, Critchley DR, Takei F: A dual role for talin in NK cell cytotoxicity: activation of LFA-1-mediated cell adhesion and polarization of NK cells. J Immunol 2009;182:948-956.

-43 Stabile H, Carlino C, Mazza C, Giliani S, Morrone S, Notarangelo LD, Notarangelo LD, Santoni A, Gismondi A: Impaired NKcell migration in WAS/XLT patients: role of Cdc42/WASp pathway in the control of chemokine-induced beta2 integrin high-affinity state. Blood 2010;115:2818-2826.

- 44 Segovis CM, Schoon RA, Dick CJ, Nacusi LP, Leibson PJ, Billadeau DD: PI3K links NKG2D signaling to a CrkL pathway involved in natural killer cell adhesion, polarity, and granule secretion. J Immunol 2009; 182:6933-6942.

45 Butler B, Kastendieck DH, Cooper JA: Differently phosphorylated forms of the cortactin homolog HS1 mediate distinct functions in natural killer cells. Nat Immunol 2008;9: 887-897. 
-46 Kinashi T: Intracellular signalling controlling integrin activation in lymphocytes. Nat Rev Immunol 2005;5:546-559.

-47 Barber DF, Faure M, Long EO: LFA-1 contributes an early signal for NK cell cytotoxicity. J Immunol 2004;173:3653-3659.

-48 Mentlik AN, Sanborn KB, Holzbaur EL, Orange JS: Rapid lytic granule convergence to the MTOC in natural killer cells is dependent on dynein but not cytolytic commitment. Mol Biol Cell 2010;21:2241-2256.

-49 Stinchcombe JC, Majorovits E, Bossi G, Fuller S, Griffiths GM: Centrosome polarization delivers secretory granules to the immunological synapse. Nature 2006;443: 462-465.

50 Mace EM, Zhang J, Siminovitch KA, Takei F: Elucidation of the integrin LFA-1-mediated signaling pathway of actin polarization in natural killer cells. Blood 2010;116:12721279.

-51 Micucci F, Capuano C, Marchetti E, Piccoli M, Frati L, Santoni A, Galandrini R: PI5KIdependent signals are critical regulators of the cytolytic secretory pathway. Blood 2008; 111:4165-4172.

52 Krzewski K, Chen X, Strominger JL: WIP is essential for lytic granule polarization and NK cell cytotoxicity. Proc Natl Acad Sci USA 2008;105:2568-2573.

-53 Quann EJ, Merino E, Furuta T, Huse M: Localized diacylglycerol drives the polarization of the microtubule-organizing center in T cells. Nat Immunol 2009;10:627-635.

54 March ME, Long EO: Beta2 integrin induces TCRz-Syk-phospholipase C-gamma phosphorylation and paxillin-dependent granule polarization in human NK cells. J Immunol 2011;186:2998-3005.

55 Meng X, Kanwar N, Du Q, Goping IS, Bleackley RC, Wilkins JA: PPP1R9B (neurabin 2): involvement and dynamics in the NK immunological synapse. Eur J Immunol 2009;39:552-560.

-56 Sancho D, Nieto M, Llano M, RodriguezFernandez JL, Tejedor R, Avraham S, Cabanas C, Lopez-Botet M, Sanchez-Madrid F: The tyrosine kinase PYK-2/RAFTK regulates natural killer (NK) cell cytotoxic response, and is translocated and activated upon specific target cell recognition and killing. J Cell Biol 2000;149:1249-1262.

-57 Li C, Ge B, Nicotra M, Stern JN, Kopcow HD, Chen X, Strominger JL: JNK MAP kinase activation is required for MTOC and granule polarization in NKG2D-mediated NK cell cytotoxicity. Proc Natl Acad Sci USA 2008; 105:3017-3022.

58 Butler B, Cooper JA: Distinct roles for the actin nucleators Arp $2 / 3$ and hDial during NKmediated cytotoxicity. Curr Biol 2009;19: 1886-1896.

59 Jiang K, Zhong B, Gilvary DL, Corliss BC, Hong-Geller E, Wei S, Djeu JY: Pivotal role of phosphoinositide-3 kinase in regulation of cytotoxicity in natural killer cells. Nat Immunol 2000;1:419-425.
60 Caraux A, Kim N, Bell SE, Zompi S, Ranson T, Lesjean-Pottier S, Garcia-Ojeda ME, Turner M, Colucci F: Phospholipase C-gamma2 is essential for NK cell cytotoxicity and innate immunity to malignant and virally infected cells. Blood 2006;107:994-1002.

61 Tassi I, Presti R, Kim S, Yokoyama WM, Gilfillan S, Colonna M: Phospholipase C\{gamma\}2 is a critical signaling mediator for murine NK cell activating receptors. J Immunol 2005;175:749-754.

62 Kim HS, Das A, Gross CC, Bryceson YT, Long EO: Synergistic signals for natural cytotoxicity are required to overcome inhibition by $\mathrm{c}-\mathrm{Cbl}$ ubiquitin ligase. Immunity 2010;32:175-186.

63 Maul-Pavicic A, Chiang SCC, Rensing-Ehl A, Jessen B, Fauriat C, Wood SM, Sjöqvist S, Hufnagel M, Schulze I, Bass T, Schamel WWA, Fuchs S, Pircher H, McCarl C-A, Mikoshiba K, Schwarz K, Feske S, Bryceson YT, Ehl S: ORAI1-mediated calcium influx is required for human cytotoxic lymphocyte degranulation and target cell lysis. Proc Natl Acad Sci USA 2011;108:3324-3329.

64 Sudhof TC, Rothman JE: Membrane fusion: grappling with SNARE and SM proteins. Science 2009;323:474-477.

65 de Saint Basile G, Menasche G, Fischer A: Molecular mechanisms of biogenesis and exocytosis of cytotoxic granules. Nat Rev Immunol 2010;10:568-579.

66 Feldmann J, Callebaut I, Raposo G, Certain $S$, Bacq D, Dumont C, Lambert N, OuacheeChardin M, Chedeville G, Tamary H, Minard-Colin V, Vilmer E, Blanche S, Le Deist F, Fischer A, de Saint Basile G: Munc13-4 is essential for cytolytic granules fusion and is mutated in a form of familial hemophagocytic lymphohistiocy tosis (FHL3). Cell 2003; 115:461-473.

67 Marcenaro S, Gallo F, Martini S, Santoro A, Griffiths GM, Arico M, Moretta L, Pende D: Analysis of natural killer-cell function in familial hemophagocytic lymphohistiocytosis (FHL): defective CD107a surface expression heralds Munc13-4 defect and discriminates between genetic subtypes of the disease. Blood 2006;108:2316-2323.

-68 Cote M, Menager MM, Burgess A, Mahlaoui N, Picard C, Schaffner C, Al-Manjomi F, AlHarbi M, Alangari A, Le Deist F, Gennery AR, Prince N, Cariou A, Nitschke P, Blank U, El-Ghazali G, Menasche G, Latour S, Fischer A, de Saint Basile G: Munc18-2 deficiency causes familial hemophagocytic lymphohistiocytosis type 5 and impairs cytotoxic granule exocytosis in patient NK cells. J Clin Invest 2009;119:3765-3773.

69 zur Stadt U, Rohr J, Seifert W, Koch F, Grieve S, Pagel J, Strauss J, Kasper B, Nurnberg G, Becker C, Maul-Pavicic A, Beutel K, Janka G, Griffiths G, Ehl S, Hennies HC: Familial hemophagocytic lymphohistiocytosis type 5 (FHL-5) is caused by mutations in Munc18-2 and impaired binding to syntaxin 11 . Am J Hum Genet 2009;85:482-492.
70 Meeths M, Entesarian M, Al-Herz W, Chiang SC, Wood SM, Al-Ateeqi W, Almazan F, Boelens JJ, Hasle H, Ifversen M, Lund B, van den Berg JM, Gustafsson B, Hjelmqvist H, Nordenskjold M, Bryceson YT, Henter JI: Spectrum of clinical presentations in familial hemophagocytic lymphohistiocytosis (FHL) type 5 patients with mutations in STXBP2. Blood 2010;116:2635-2643.

71 Stinchcombe JC, Barral DC, Mules EH, Booth S, Hume AN, Machesky LM, Seabra MC, Griffiths GM: Rab27a is required for regulated secretion in cytotoxic T lymphocytes. J Cell Biol 2001;152:825-834.

72 Menasche G, Menager MM, Lefebvre JM, Deutsch E, Athman R, Lambert N, Mahlaoui N, Court M, Garin J, Fischer A, de Saint Basile G: A newly identified isoform of Slp2a associates with Rab27a in cytotoxic T cells and participates to cytotoxic granule secretion. Blood 2008; 112:5052-5062.

73 Holt O, Kanno E, Bossi G, Booth S, Daniele T, Santoro A, Arico M, Saegusa C, Fukuda M, Griffiths GM: Slp1 and Slp2-a localize to the plasma membrane of CTL and contribute to secretion from the immunological synapse. Traffic 2008;9:446-457.

-74 Menager MM, Menasche G, Romao M, Knapnougel P, Ho CH, Garfa M, Raposo G, Feldmann J, Fischer A, de Saint Basile G: Secretory cytotoxic granule maturation and exocytosis require the effector protein hMunc13-4. Nat Immunol 2007;8:257-267.

-75 Wood SM, Meeths M, Chiang SC, Bechensteen AG, Boelens JJ, Heilmann C, Horiuchi H, Rosthoj S, Rutynowska O, Winiarski J, Stow JL, Nordenskjold M, Henter JI, Ljunggren HG, Bryceson YT: Different NK cellactivating receptors preferentially recruit Rab27a or Munc13-4 to perforin-containing granules for cytotoxicity. Blood 2009;114: 4117-4127.

76 Lee SH, Yun S, Lee J, Kim MJ, Piao ZH, Jeong M, Chung JW, Kim TD, Yoon SR, Greenberg PD, Choi I: RasGRP1 is required for human NK cell function. J Immunol 2009;183:79317938.

$\checkmark 77$ Giurisato E, Lin J, Harding A, Cerutti E, Cella M, Lewis RE, Colonna M, Shaw AS: The mitogen-activated protein kinase scaffold KSR1 is required for recruitment of extracellular signal-regulated kinase to the immunological synapse. Mol Cell Biol 2009;29:15541564.

78 Sanborn KB, Rak GD, Maru SY, Demers K, Difeo A, Martignetti JA, Betts MR, Favier R, Banerjee PP, Orange JS: Myosin IIA associates with NK cell lytic granules to enable their interaction with F-actin and function at the immunological synapse. J Immunol 2009;182:6969-6984.

79 Kim N, Saudemont A, Webb L, Camps M, Ruckle T, Hirsch E, Turner M, Colucci F: The p110delta catalytic isoform of PI3K is a key player in NK-cell development and cytokine secretion. Blood 2007;110:3202-3208. 
80 Tassi I, Cella M, Gilfillan S, Turnbull I, Diacovo TG, Penninger JM, Colonna M: p110gamma and p110delta phosphoinositide 3-kinase signaling pathways synergize to control development and functions of murine NK cells. Immunity 2007;27:214-227.

-81 Tassi I, Cella M, Presti R, Colucci A, Gilfillan S, Littman DR, Colonna M: NK cell-activating receptors require PKC-theta for sustained signaling, transcriptional activation, and IFN-gamma secretion. Blood 2008;112: 4109-4116.
Arneson LN, Segovis CM, Gomez TS, Schoon RA, Dick CJ, Lou Z, Billadeau DD, Leibson PJ: Dynamin 2 regulates granule exocytosis during NK cell-mediated cytotoxicity. J Immunol 2008;181:6995-7001.

83 Davis DM: Mechanisms and functions for the duration of intercellular contacts made by lymphocytes. Nat Rev Immunol 2009;9: 543-555.

84 Rudd E, Bryceson YT, Zheng C, Edner J, Wood SM, Ramme K, Gavhed S, Gurgey A, Hellebostad M, Bechensteen A, Ljunggren HG, Fadeel B, Nordenskjold M, Henter JI: Spectrum, and clinical and functional implications of UNC13D mutations in familial hemophagocytic lymphohistiocytosis. J Med Genet 2008;45:134-141.
85 Gismondi A, Cifaldi L, Mazza C, Giliani S, Parolini S, Morrone S, Jacobelli J, Bandiera E, Notarangelo L, Santoni A: Impaired natural and CD16-mediated NK cell cytotoxicity in patients with WAS and XLT: ability of IL-2 to correct NK cell functional defect. Blood 2004;104:436-443.

86 Lee SH, Yun S, Piao ZH, Jeong M, Kim DO, Jung H, Lee J, Kim MJ, Kim MS, Chung JW, Kim TD, Yoon SR, Greenberg PD, Choi I: Suppressor of cytokine signaling 2 regulates IL-15-primed human NK cell function via control of phosphorylated Pyk2. J Immunol 2010;185:917-928. 